\title{
PREDICTION OF ENERGY EXPENDITURE FROM PEDOMETER OUTPUT ACROSS DIFFERENT ACTIVITIES IN YOUNG HEALTHY ADULTS
}

original paper

( ) University School of Physical Education in Wroclaw

DOI: https://doi.org/10.5114/hm.2019.81022

\author{
PORAM CHOI ${ }^{1}$, ROLAND O. WEBSTER IV ${ }^{2}$, STAMATIS AGIOVLASITIS ${ }^{1}$ \\ ${ }^{1}$ Department of Kinesiology, Mississippi State University, Starkville, USA \\ ${ }^{2}$ Drayer Physical Therapy Institute, Covington, USA
}

\section{ABSTRACT}

Purpose. The New Lifestyles NL-1000 pedometer is a suitable device for cost-efficient assessment and promotion of physical activity owing to low cost and accuracy. This study examined if step rate as determined by the NL-1000 pedometer predicted the rate of oxygen uptake (VO2) across different activity types in young healthy adults and evaluated the accuracy of such prediction. It was also investigated if height, body mass index (BMI), and sex contributed to the prediction.

Methods. The study involved 36 healthy young adults ( $21 \pm 4$ years; 16 women). The participants completed 8 activities, each lasting 6 minutes: (a) sitting; (b) slow walking; (c) fast walking; (d) jogging; (e) moving a box; (f) washing dishes; (g) ascending-descending stairs; and $(\mathrm{h})$ vacuuming. We measured $\mathrm{VO}_{2}$ with a portable open-circuit spirometer and step rate with the NL-1000 pedometer worn on the non-dominant hip. We used multi-level regression to predict $\mathrm{VO}_{2}$ and determined the absolute percent error of the $\mathrm{VO}_{2}$ prediction model with the leave-one-participant-out cross-validation procedure.

Results. Significant predictors of $\mathrm{VO}_{2}$ were step rate and its square $\left(p<0.001 ; R^{2}=0.72\right)$, but not height, BMI, or sex. Absolute error across all activities combined was $29.7 \pm 27.6 \%$. Absolute error differed between activities $(p<0.001)$.

Conclusions. Pedometer-determined step rate and its square were significant predictors of $\mathrm{VO}_{2}$ across different activities in healthy young adults. Height, BMI, or sex did not contribute to $\mathrm{VO}_{2}$ prediction. Accuracy of prediction across activities was low to moderate.

Key words: step rate, height, oxygen uptake, physical activity

\section{Introduction}

Physical activity (PA) has numerous health benefits and can prevent cardiovascular disease, type 2 diabetes, some cancers, and all-cause mortality [1]. To obtain health benefits, adults should participate in at least $150 \mathrm{~min} \cdot \mathrm{wk}^{-1}$ of moderate-intensity PA or $75 \mathrm{~min} \cdot \mathrm{wk}^{-1}$ of vigorous intensity aerobic $\mathrm{PA}$, or an equivalent combination of moderate and vigorous-intensity PA [2]. However, only $21 \%$ of adults in the United States meet the recommended level of PA [3]. The data show a need for effective and feasible PA promotion.

For effective PA promotion, we need an easy and accurate device of quantifying PA levels. PA intensity can be assessed by measuring the rate of oxygen uptake $\left(\mathrm{VO}_{2}\right)$ - an index of energy expenditure. $\mathrm{VO}_{2}$ can be directly evaluated with open-circuit spirometry; this method, however, is expensive and cumbersome. Therefore, researchers and practitioners utilize indirect methods for estimating PA intensity. Pedometers provide a simpler and inexpensive objective approach to PA assessment, as well as immediate feedback to individual users [4]. They can also be applied as motivational tools for encouraging people to participate in PA [5].

Pedometers measure steps and allow determination of step rate (steps $\cdot \mathrm{min}^{-1}$ ), which is a known determinant of $\mathrm{VO}_{2}$ during locomotion [6]. Consequently, researchers have used pedometer-determined step rate for estimating $\mathrm{VO}_{2}$ and have developed step-rate thresholds for PA intensity [7-10]. To this end, the step rate of $100 \mathrm{steps} \cdot \mathrm{min}^{-1}$ has been identified as a threshold for moderate-to-vigorous PA or 3 METs (1 MET is the average resting $\mathrm{VO}_{2}$ or $3.5 \mathrm{ml} \cdot \mathrm{kg}^{-1} \cdot \mathrm{min}^{-1}$ ) [7-9]. Other researchers, however, have shown that the thresh-

Correspondence address: Poram Choi, Mississippi State University, Department of Kinesiology, 224 McCarthy Gym, Mississippi State, MS 39762, USA, e-mail: pc839@msstate.edu

Received: October 25, 2018

Accepted for publication: November 26, 2018

Citation: Choi P, Webster IV RO, Agiovlasitis S. Prediction of energy expenditure from pedometer output across different activities in young healthy adults. Hum Mov. 2019;20(2):64-71; doi: https://doi.org/10.5114/hm.2019.81022. 
old varies as a function of leg length or height [11, 12]. This is logical because height and leg length are associated with step length, which is another determinant of $\mathrm{VO}_{2}$ during locomotion [6]. Although height is a determinant of $\mathrm{VO}_{2}$, whether height contributes to $\mathrm{VO}_{2}$ prediction from step rate across locomotor and nonlocomotor activities has not been examined and more research is needed. As step rate is primarily relevant for locomotion, most previous pedometer studies have focused on locomotion activities [12-14]. However, daily PA is not limited to locomotion, and there is a need to examine how accurate pedometer output is in predicting $\mathrm{VO}_{2}$ during other activities of daily living. Finally, it has also been demonstrated that sex and body mass index (BMI) are associated with $\mathrm{VO}_{2}$ [15]; thus, research is necessary to establish the extent to which easily determined factors can improve the prediction of $\mathrm{VO}_{2}$ from pedometer output.

Furthermore, the accuracy of predicting energy cost varies with pedometer type, and the developed equations depend on the activities [15-17]. Therefore, there is a need for more research in examining the extent to which output from other pedometers can be utilized in estimating the $\mathrm{VO}_{2}$, and PA intensity, during different activities of daily living. An electronic pedometer that has been recommended for use in research and PA promotion is the New Lifestyles NL-1000 pedometer $[18,19]$. The NL-1000 pedometer has acceptable accuracy in measuring steps not only in laboratory but also in free-living conditions [20]. The NL1000 has the same piezo-electric mechanism with the NL-2000, which is known as an accurate pedometer [21], but it is cheaper than the NL-2000. The NL-1000 pedometer might be suitable for cost-efficient assessment and promotion of PA owing to its low cost and accuracy. However, the ability of this pedometer to predict $\mathrm{VO}_{2}$ during different activities has not been examined.

Therefore, the purpose of this study was to examine whether step rate as determined with the NL-1000 pedometer, height, sex, and BMI predict $\mathrm{VO}_{2}$ across different types of activities in healthy young adults and to evaluate the accuracy of such a prediction model. We hypothesized that step rate would be a significant predictor of $\mathrm{VO}_{2}$ and that there would be differences in $\mathrm{VO}_{2}$ predictability among the different activities.

\section{Material and methods}

\section{Participants}

Overall, 36 healthy adults (16 women and 20 men; age: $21 \pm 4$ years) participated in this study. Their anthropometric variables were as follows: height: 170.7 $\pm 9.8 \mathrm{~cm}$; weight: $69.3 \pm 13.3 \mathrm{~kg}$; and BMI: $23.6 \pm$ $3.1 \mathrm{~kg} / \mathrm{m}^{2}$. We recruited the participants from the university and the surrounding communities. They were included in the study if they were adults aged 18-45 years, without known cardiovascular, pulmonary, neuromuscular, or orthopaedic problems, and without mobility difficulties - this information was obtained with a health history questionnaire.

\section{Procedures}

The subjects attended a data collection session and their anthropometric variables were obtained, and steps and $\mathrm{VO}_{2}$ were measured at rest and during a set of tasks. They had refrained from food and caffeine for 3 hours, and from exercise for 24 hours prior to the session. At the beginning of the session, we measured height in $\mathrm{cm}$ with a portable stadiometer (213, Seca, USA) and weight in $\mathrm{kg}$ with a scale (813, Seca, USA), and we determined BMI in $\mathrm{kg} \cdot \mathrm{m}^{-2}$. We then fitted the participants with the data collection equipment described below and had them sit quietly for $10 \mathrm{~min}$ to ensure that they adequately rested from any possible activity level prior to coming to the laboratory.

Thereafter, we collected data during sitting, 3 locomotion activities, and 4 other activities of daily living. The sitting period and each activity trial lasted $6 \mathrm{~min}$. Sitting was always conducted first. The order of the locomotion activities and other activities of daily living was randomized. Half of the participants completed the locomotion activities first, and the other half carried out the other activities of daily living first.

Locomotion activities were performed on a treadmill (Woodway Pro, Waukesha, USA) and included: walking at $1.12 \mathrm{~m} \cdot \mathrm{s}^{-1}(2.5 \mathrm{mph})$ with $0 \%$ grade; walking at $1.57 \mathrm{~m} \cdot \mathrm{s}^{-1}(3.5 \mathrm{mph})$ with $5 \%$ grade; and jogging at $2.24 \mathrm{~m} \cdot \mathrm{s}^{-1}(5 \mathrm{mph})$ with $0 \%$ grade. Other activities of daily living included: washing dishes; vacuuming a carpeted floor area of $7.6 \mathrm{~m}^{2}$ covered with shredded paper; moving a box weighing $5 \mathrm{~kg}$ between 2 carts approximately $7 \mathrm{~m}$ away; and ascending and descending a 20-step staircase with steps $20.3 \mathrm{~cm}$ in height. These activities were selected in an attempt to include a sample of locomotor, household, and occupational activities of various intensities on the basis of past research [16, 22]. We asked the participants to perform these other activities of daily living at their preferred pace for 6 min each. The subjects rested while sitting for 6 min between the activity trials to allow $\mathrm{VO}_{2}$ to reach resting levels, thus eliminating any possible carry-over effects on energy expenditure. 
We measured relative gross $\mathrm{VO}_{2}$ in $\mathrm{ml} \cdot \mathrm{kg}^{-1} \cdot \mathrm{min}^{-1}$ using a breath-by-breath portable metabolic system (K4b ${ }^{2}$, Cosmed, Chicago, USA). We calibrated this system 1 hour prior to each data collection session following the procedure specified by the manufacturer. $\mathrm{VO}_{2}$ was determined as the average over the last $3 \mathrm{~min}$ of each activity. We measured the participants' weight in $\mathrm{kg}$ while wearing shoes and all equipment for determining $\mathrm{VO}_{2}$. The subjects also wore the NL-1000 pedometer (New Lifestyles, Inc., Lee’s Summit, USA) on their non-dominant hip with a waist-strap. We recorded the steps during each 6-min trial and divided the total steps by 6 min to determine the step rate in steps $\cdot \min ^{-1}$. We used step rate because this variable has a known relationship with $\mathrm{VO}_{2}$ during locomotion and has been recommended as one that can classify PA intensity [9, 23].

\section{Statistical analysis}

To develop an equation predicting $\mathrm{VO}_{2}$, we used multi-level modelling because, unlike simple regression, this type of regression accounts for the nesting of multiple observations within each participant [24]. Possible predictors (fixed effects) included step rate, step rate square, height, BMI, and sex. Step rate square was considered because, upon visual inspection of the data, the relationship between $\mathrm{VO}_{2}$ and step rate appeared curvilinear. Potential random effects were the intercepts and slopes of the $\mathrm{VO}_{2}$ to step rate relationship across participants. We developed the model gradually, starting with step rate, and then tested additional factors. We evaluated the inclusion of fixed and random effects to the model by the difference in -2 log-likelihood between models against a $\chi^{2}$ distribution with one degree of freedom.

We then attempted to cross-validate the regression model with the leave-one-participant-out approach [25]. Specifically, we ran the multi-level regression model on the data from all participants except one (the left-out participant). We then used the resulting regression coefficients to predict the $\mathrm{VO}_{2}$ data points for the left-out participant. We conducted this procedure 36 times, until the data from all 36 subjects were used for cross-validation. Thus, we had the actual $\mathrm{VO}_{2}$ and the estimated $\mathrm{VO}_{2}$ across tasks for each of the 36 left-out participants.

We statistically tested differences between actual and estimated $\mathrm{VO}_{2}$ across activities using mixed-model (method by task) within-subject analysis of variance (ANOVA). We applied the Greenhouse-Geisser adjustment when compound symmetry was violated on the basis of Mauchly's test and, in the presence of significant interaction, we conducted dependent-samples $t$-tests between methods for each task with Bonferroni-adjusted alpha $(0.05 / 8=0.006)$.

We further calculated the absolute percent error for the left-out participant at each task and across all tasks combined as the absolute value:

$$
\left[\left(\text { actual } \mathrm{VO}_{2} \text { - estimated } \mathrm{VO}_{2}\right) / \text { actual } \mathrm{VO}_{2}\right] \times 100
$$

Finally, we evaluated the agreement between actual and estimated $\mathrm{VO}_{2}$ for left-out participants with Bland-Altman plots separately for each activity and all activities combined [26]. Statistical analyses were run in the SPSS Statistics 23 software (IBM, Armonk, USA), and the alpha level was 0.05 when not adjusted for multiple comparisons.

\section{Ethical approval}

The research related to human use has been complied with all the relevant national regulations and institutional policies, has followed the tenets of the Declaration of Helsinki, and has been approved by the authors' institutional review board.

\section{Informed consent}

Informed consent has been obtained from all individuals included in this study.

\section{Results}

Significant predictors of $\mathrm{VO}_{2}$ in the multi-level regression model were step rate and its square $(p<0.001$; $R^{2}=0.72$; Table 1, Figure 1). Height, sex, or BMI were not significant predictors of $\mathrm{VO}_{2}$. The model included random intercepts. Random slopes were not a significant factor in the model.

There were differences between actual and estimated $\mathrm{VO}_{2}$ across tasks as shown by significant method by task interaction in within-subject ANOVA $(p<0.001$; Table 2). The $\mathrm{VO}_{2}$ estimated with the regression model

Table 1. Multi-level regression model predicting the rate of oxygen uptake $\left(\mathrm{VO}_{2}\right)\left(\mathrm{ml} \cdot \mathrm{kg}^{-1} \cdot \mathrm{min}^{-1}\right)$ from step rate

\begin{tabular}{|c|c|c|}
\hline & \\
\hline & $\mathrm{b}$ & SE \\
\hline Intercept ${ }^{*}$ & 7.6296 & 0.5336 \\
\hline Step rate $\left(\text { steps } \cdot \min ^{-1}\right)^{*}$ & 0.0872 & 0.0168 \\
\hline Step rate ${ }^{2}\left[\left(\text { steps } \cdot \min ^{-1}\right)^{2}\right]^{*}$ & 0.0004 & 0.0001 \\
\hline
\end{tabular}

$b$ - unstandardized coefficient, $S E$ - standard error ${ }^{*} p<0.001, R^{2}=0.72$ 

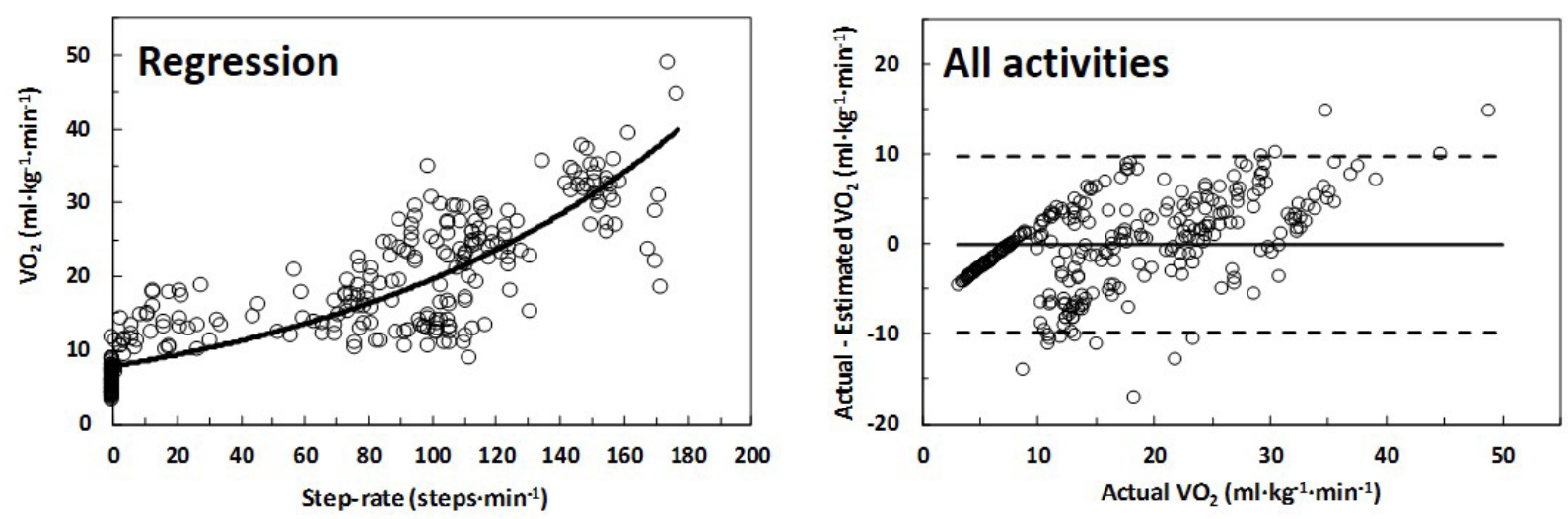

Figure 1. Left panel: rate of oxygen uptake $\left(\mathrm{VO}_{2}\right)$ as a function of step rate across tasks. The solid line is the mean regression using the coefficients from Table 1. Right panel: Bland-Altman plot of the difference between actual and estimated $\mathrm{VO}_{2}$ as a function of actual $\mathrm{VO}_{2}$ for all 8 tasks combined. Solid and dotted lines are mean and 95\% limits of agreement, respectively

was higher than the actual $\mathrm{VO}_{2}$ for sitting and walking at $1.12 \mathrm{~m} \cdot \mathrm{s}^{-1}(p<0.001)$; however, the estimated $\mathrm{VO}_{2}$ was lower than the actual $\mathrm{VO}_{2}$ for ascending and descending stairs and for vacuuming $(p<0.001)$. There were no statistically significant differences between actual and estimated $\mathrm{VO}_{2}$ for the remaining activities. Absolute error across all activities combined was 29.7 $\pm 27.6 \%$. From a descriptive stand-point, there were differences between tasks in absolute percent error (Table 2); absolute percent error was very high for sitting and walking at $1.12 \mathrm{~m} \cdot \mathrm{s}^{-1}$, and it was lowest for walking at $1.57 \mathrm{~m} \cdot \mathrm{s}^{-1}$.

The Bland-Altman plot across all tasks combined showed that the difference between actual and estimated $\mathrm{VO}_{2}$ was on average nearly zero; however, there was large variation in the difference among individual data points (Figure 1). Visual inspection of the separate plots for the 8 tasks showed overestimation of $\mathrm{VO}_{2}$ for walking at $1.12 \mathrm{~m} \cdot \mathrm{s}^{-1}$ and sitting, and underestimation for ascending-descending stairs and vacuum- ing; for the remaining tasks, there was no evidence of mean overestimation or underestimation (Figure 2). Furthermore, the predictability of individual scores varied to a substantial extent within and between tasks.

\section{Discussion}

The presented study examined whether step rate as determined by the NL-1000 electronic pedometer predicted $\mathrm{VO}_{2}$ across different activities in young healthy adults. The main findings were that pedometer-determined step rate and its square constituted significant predictors of $\mathrm{VO}_{2}$, but height, $\mathrm{BMI}$, and sex did not contribute to the prediction. The accuracy of the prediction model was reasonable across all activities combined, but varied across different activities.

Step rate and its square were significant predictors of $\mathrm{VO}_{2}$. Step rate determines walking speed together with step length [6]; thus, it is not surprising that step rate contributed to the prediction. The inclusion of step

Table 2. Step rate, actual and estimated rate of oxygen uptake $\left(\mathrm{VO}_{2}\right)$, and absolute percent error of the predictive model across different tasks

\begin{tabular}{lcccc}
\hline Task & $\begin{array}{c}\text { Step rate } \\
\left(\text { steps } \cdot \mathrm{min}^{-1}\right)\end{array}$ & $\begin{array}{c}\text { Actual VO } \\
\left(\mathrm{ml} \cdot \mathrm{kg}^{-1} \cdot \mathrm{min}^{-1}\right)\end{array}$ & $\begin{array}{c}\text { Estimated } \mathrm{VO}_{2} \\
\left(\mathrm{ml} \cdot \mathrm{kg}^{-1} \cdot \mathrm{min}^{-1}\right)\end{array}$ & Absolute error $(\%)$ \\
\hline Sitting & $0.0 \pm 0.0$ & $4.8 \pm 0.9$ & $7.6 \pm 0.0^{*}$ & $67.5 \pm 29.8$ \\
Walking $1.12 \mathrm{~m} \cdot \mathrm{s}^{-1} ; 0 \%$ grade & $101.7 \pm 7.7$ & $13.0 \pm 1.9$ & $20.6 \pm 1.3^{*}$ & $62.7 \pm 25.7$ \\
Walking $1.57 \mathrm{~m} \cdot \mathrm{s}^{-1} ; 5 \%$ grade & $117.5 \pm 6.7$ & $23.6 \pm 2.8$ & $23.4 \pm 1.3$ & $11.2 \pm 13.1$ \\
Jogging 2.24 $\mathrm{m} \cdot \mathrm{s}^{-1} ; 0 \%$ grade & $153.6 \pm 8.8$ & $31.3 \pm 4.4$ & $30.4 \pm 2.0$ & $16.4 \pm 17.6$ \\
Moving box & $71.1 \pm 13.6$ & $15.4 \pm 2.8$ & $15.9 \pm 1.8$ & $15.3 \pm 13.9$ \\
Washing dishes & $0.2 \pm 0.3$ & $7.4 \pm 1.4$ & $7.6 \pm 0.1$ & $15.3 \pm 15.8$ \\
Ascending-descending stairs & $102.4 \pm 20.2$ & $26.9 \pm 6.0$ & $20.8 \pm 3.7^{*}$ & $21.6 \pm 8.3$ \\
Vacuuming & $17.1 \pm 13.0$ & $13.5 \pm 3.0$ & $9.3 \pm 1.4^{*}$ & $28.9 \pm 13.5$ \\
\hline
\end{tabular}

${ }^{*} p<0.001$ in dependent-samples $t$-tests between actual and estimated $\mathrm{VO}_{2}$ 
P. Choi, R.O. Webster IV, S. Agiovlasitis, Prediction of $\mathrm{VO}_{2}$ from pedometer output
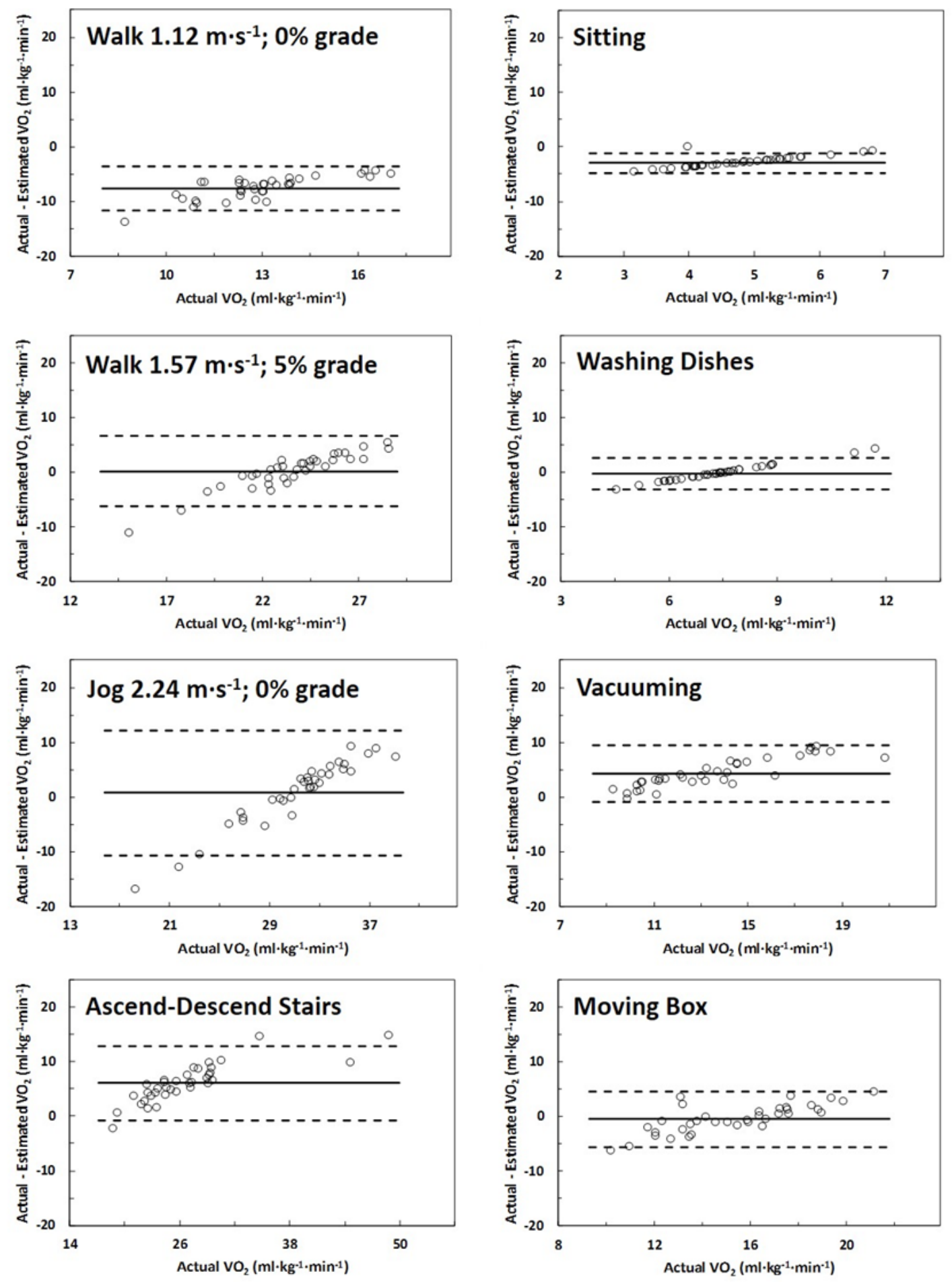

Figure 2. Bland-Altman plots of the difference between actual and estimated rate of oxygen uptake $\left(\mathrm{VO}_{2}\right)$ as a function of actual $\mathrm{VO}_{2}$ for each of the 8 tasks. Solid and dotted lines are mean and 95\% limits of agreement, respectively

rate square in the model was justified by the curvilinear nature of the relationship between step rate and $\mathrm{VO}_{2}$, a finding in accord with past research [8, 10]. Our finding, however, that height, BMI, or sex did not significantly contribute to $\mathrm{VO}_{2}$ prediction contrasts with previous research $[11,15]$. The disparity between previous studies and our observations could possibly be due to methodological differences. Our protocol involved various activities of daily living, including non-locomotion ones, to examine the relationship between step rate and energy expenditure. In contrast, previous studies used only locomotion activities, during which height can determine step length - another known determinant of energy expenditure [6]. 
Nevertheless, step rate and its square explained a remarkable portion (72\%) of the variance in $\mathrm{VO}_{2}$ and mean error in the Bland-Altman plot was nearly zero, indicating a high potential of the resultant model to accurately predict $\mathrm{VO}_{2}$ across locomotor and non-locomotor activities combined. Although the average difference between actual and predicted $\mathrm{VO}_{2}$ in the BlandAltman plot across all activities was negligible, the absolute error across all activities combined was relatively large. The magnitude of absolute error seems to primarily be the outcome of the differences in prediction error between different activities. Most notable was the high absolute error during sitting and slow walking, which largely influenced the error across all activities combined. Collectively, our findings indicate that step rate and step rate square can be used to estimate energy expenditure; however, predictability differs between different tasks.

A better picture of the predictability of $\mathrm{VO}_{2}$ from step-rate arises when examining the absolute error with Bland-Altman plots separately for each activity. The model showed reasonable estimates of $\mathrm{VO}_{2}$ for some activities: fast walking with 5\% incline, jogging, moving boxes, and washing dishes. However, the model overestimated $\mathrm{VO}_{2}$ during sitting and slow walking, and underestimated $\mathrm{VO}_{2}$ during ascending-descending stairs and vacuuming.

These findings are in general agreement with previous research. It is known that pedometers are generally accurate in measuring steps during locomotion [13, $14,21]$. However, they tend to underestimate steps during slow walking $[13,14]$. Also, the model overestimated the $\mathrm{VO}_{2}$ during sitting, which may be the outcome of a relatively large intercept $\left(7.6296 \mathrm{ml} \cdot \mathrm{kg}^{-1} \cdot \mathrm{min}^{-1}\right)$.

The underestimation of $\mathrm{VO}_{2}$ during ascending-descending stairs was also in agreement with past findings $[27,28]$. Although this task requires more $\mathrm{VO}_{2}$ than over-ground walking $[27,28]$, pedometers cannot differentiate the movement between the walking and ascending-descending stairs [29]. Underestimation of $\mathrm{VO}_{2}$ during vacuuming was also reported previously $[16,17]$, a finding that may relate to upper-body movements, which increase the energy expenditure but cannot be captured by pedometers.

This underestimation might relate to the curvilinear term included in our prediction model. A curvilinear model tends to increase the $y$-intercept of the $\mathrm{VO}_{2}$ to step rate relationship compared with a linear model. However, this curvilinear function and high intercept may have produced the finding of greater accuracy during washing dishes compared with sitting. Although equations developed with pedometer out- put tend to underestimate energy expenditure during upper-body activities [16, 17, 27], the curvilinear function likely resulted in better estimates of $\mathrm{VO}_{2}$ during dishwashing, when upper-body muscular activity occurs at nearly-zero step rates. Curvilinear terms have previously been included in equations for predicting $\mathrm{VO}_{2}$ from step rate $[8,10]$.

Other models, however, have included only linear terms for step rate $[7,12,30]$. Although equations with quadratic terms are more complicated, the inclusion of step rate square is substantiated on the basis of previous research demonstrating that the energy expenditure of locomotion is a curvilinear function of step rate [6]. Furthermore, Abel et al. [8] demonstrated that a curvilinear model had better predictability of energy expenditure across different speeds of locomotion than a linear model. In summary, our findings indicate that predictability of $\mathrm{VO}_{2}$ from pedometer output varies across different tasks.

The results of this study have implications for PA research and intervention programs. Using our prediction equation, we can calculate that the step-rate threshold for moderate-intensity PA (defined as step rate at $10.5 \mathrm{ml} \cdot \mathrm{kg}^{-1} \cdot \mathrm{min}^{-1}$ or 3 METs) was 102 steps - $\mathrm{min}^{-1}$. This value is nearly identical to the previous general recommendation of reaching $100 \mathrm{steps} \cdot \mathrm{min}^{-1}$ for moderate-intensity walking [7, 9]. This finding, taken together with the relatively high predictability of the regression model across activities observed herein, indicates that the NL-1000 pedometer has reasonable potential in monitoring PA activity levels throughout the day in young healthy adults.

As discussed earlier, however, step rate seemed to misclassify the intensity for several activities. For example, moving boxes and vacuuming were performed at moderate intensity by our participants, but the step rates were 71 and 17 steps $\cdot \mathrm{min}^{-1}$, respectively - below the calculated moderate-intensity threshold. And, although the step rate during ascending-descending stairs was at the moderate-intensity threshold (102 steps $\left.\cdot \mathrm{min}^{-1}\right)$, the actual intensity was vigorous $\left(27 \mathrm{ml} \cdot \mathrm{kg}^{-1} \cdot \mathrm{min}^{-1}\right.$ or $\left.7.7 \mathrm{METs}\right)$.

Therefore, PA professionals should use the NL-1000 electronic pedometer with caution when attempting to engage people in non-locomotor activities of various intensities. Professionals may apply this pedometer with greater confidence for engaging people in locomotion activities of moderate-to-vigorous intensity. This is particularly important since walking is the most commonly performed PA [31].

The following limitations of the present study should be considered. First, the results may not gen- 
P. Choi, R.O. Webster IV, S. Agiovlasitis, Prediction of $\mathrm{VO}_{2}$ from pedometer output

eralize to other types of pedometers because we used a specific pedometer model. Second, our sample was limited to young healthy individuals; thus, the prediction model may not apply to children, older adults, and people with health conditions. Finally, the magnitude of error for some of the activities may be associated with the fact that they were self-paced and may have had an intermittent nature, which influences the $\mathrm{VO}_{2}$.

However, the study also had noticeable strengths. It is the first study that developed a model for predicting $\mathrm{VO}_{2}$ with output from the NL-1000 electronic pedometer. We elaborated the prediction equation based on many different activities, including non-locomotor activities. We cross-validated the prediction equation with the leave-one-participant-out crossvalidation procedure, which increases our confidence in the results. And we used multi-level modelling, which accounts for the nesting of observations within each participant.

Future research could examine the accuracy of pedometers in predicting $\mathrm{VO}_{2}$ during free-living activities. It would also be valuable to test the accuracy of several different pedometers and different placement sites.

\section{Conclusions}

In conclusion, step rate and its square as measured by the NL-1000 electronic pedometer are significant predictors of $\mathrm{VO}_{2}$ across different activities in healthy young adults. Height, BMI, or sex do not contribute to $\mathrm{VO}_{2}$ prediction. The accuracy of the prediction across activities is low to moderate. The NL-1000 pedometer has the potential to monitor PA levels across different activities in young healthy adults.

\section{Disclosure statement}

No author has any financial interest or received any financial benefit from this research.

\section{Conflict of interest}

The authors state no conflict of interest.

\section{References}

1. Lee IM, Shiroma EJ, Lobelo F, Puska P, Blair SN, Katzmarzyk PT, et al. Effect of physical inactivity on major non-communicable diseases worldwide: an analysis of burden of disease and life expectancy. Lancet. 2012;380(9838):219-229; doi: 10.1016/S0140-6736(12) 61031-9.
2. World Health Organization. Global recommendations on physical activity for health. Geneva: World Health Organization; 2010.

3. Centers for Disease Control and Prevention. Facts about physical activity. Available from: https://www.cdc.gov/ physicalactivity/data/facts.htm.

4. Kang M, Marshall SJ, Barreira TV, Lee JO. Effect of pedometer-based physical activity interventions: a meta-analysis. Res Q Exerc Sport. 2009;80(3):648-655; doi: 10.1080/02701367.2009.10599604.

5. Bravata DM, Smith-Spangler C, Sundaram V, Gienger AL, Lin N, Lewis R, et al. Using pedometers to increase physical activity and improve health: a systematic review. JAMA. 2007;298(19):2296-2304; doi: 10.1001/ jama.298.19.2296.

6. Kuo AD. The six determinants of gait and the inverted pendulum analogy: a dynamic walking perspective. Hum Mov Sci. 2007;26(4):617-656; doi: 10.1016/ j.humov.2007.04.003.

7. Marshall SJ, Levy SS, Tudor-Locke CE, Kolkhorst FW, Wooten KM, Ji M, et al. Translating physical activity recommendations into a pedometer-based step goal: 3000 steps in 30 minutes. Am J Prev Med. 2009;36(5): 410-415; doi: 10.1016/j.amepre.2009.01.021.

8. Abel M, Hannon J, Mullineaux D, Beighle A. Determination of step rate thresholds corresponding to physical activity intensity classifications in adults. J Phys Act Health. 2011;8(1):45-51; doi: 10.1123/jpah.8.1.45.

9. Tudor-Locke C, Bassett DR Jr. How many steps/day are enough? Preliminary pedometer indices for public health. Sports Med. 2004;34(1):1-8; doi: 10.2165/0000 7256-200434010-00001.

10. Agiovlasitis S, Beets MW, Motl RW, Fernhall B. Steprate thresholds for moderate and vigorous-intensity activity in persons with Down syndrome. J Sci Med Sport. 2012;15(5):425-430; doi: 10.1016/j.jsams.2012. 03.001.

11. Beets MW, Agiovlasitis S, Fahs CA, Ranadive SM, Fernhall B. Adjusting step count recommendations for anthropometric variations in leg length. J Sci Med Sport. 2010;13(5):509-512; doi: 10.1016/j.jsams.2009.11.002.

12. Rowe DA, Welk GJ, Heil DP, Mahar MT, Kemble CD, Calabró MA, et al. Stride rate recommendations for moderate-intensity walking. Med Sci Sports Exerc. 2011;43(2):312-318; doi: 10.1249/MSS.0b013e3181e 9d99a.

13. Beets MW, Patton MM, Edwards S. The accuracy of pedometer steps and time during walking in children. Med Sci Sports Exerc. 2005;37(3):513-520; doi: 10.1249/01.MSS.0000155395.49960.31.

14. Park W, Lee VJ, Ku B, Tanaka H. Effect of walking speed and placement position interactions in determining the accuracy of various newer pedometers. J Exerc Sci Fit. 2014;12(1):31-37; doi: 10.1016/j.jesf.2014. 01.003.

15. Nielson R, Vehrs PR, Fellingham GW, Hager R, Prusak KA. Step counts and energy expenditure as esti- 
mated by pedometry during treadmill walking at different stride frequencies. J Phys Act Health. 2011;8(7): 1004-1013; doi: 10.1123/jpah.8.7.1004.

16. Bassett DR Jr, Ainsworth BE, Swartz AM, Strath SJ, O’Brien WL, King GA. Validity of four motion sensors in measuring moderate intensity physical activity. Med Sci Sports Exerc. 2000;32(9 Suppl):S471-S480; doi: 10.1097/00005768-200009001-00006.

17. Strath SJ, Bassett DR Jr, Swartz AM, Thompson DL. Simultaneous heart rate-motion sensor technique to estimate energy expenditure. Med Sci Sports Exerc. 2001;33(12):2118-2123; doi: 10.1097/00005768-200 112000-00022.

18. Stackpool CM, Porcari JP, Mikat RP, Gillette C, Foster C. The accuracy of various activity trackers in estimating steps taken and energy expenditure. J Fit Res. 2014;3(3):32-48.

19. Barreira TV, Brouillette RM, Foil HC, Keller JN, Tudor-Locke C. Comparison of older adults' steps per day using an NL-1000 pedometer and two GT3X+ accelerometer filters. J Aging Phys Act. 2013;21(4):402-416.

20. McMinn D, Rowe DA, Stark M, Nicol L. Validity of the New Lifestyles NL-1000 accelerometer for measuring time spent in moderate-to-vigorous physical activity in school settings. Meas Phys Educ Exerc Sci. 2010; 14(2):67-78; doi: 10.1080/10913671003715516.

21. Crouter SE, Schneider PL, Bassett DR Jr. Spring-levered versus piezo-electric pedometer accuracy in overweight and obese adults. Med Sci Sports Exerc. 2005;37(10): 1673-1679; doi: 10.1249/01.mss.0000181677.36658.a8.

22. Ainsworth BE, Haskell WL, Herrmann SD, Meckes N, Bassett DR Jr, Tudor-Locke C, et al. 2011 Compendium of Physical Activities: a second update of codes and MET values. Med Sci Sports Exerc. 2011;43(8): 1575-1581; doi: 10.1249/MSS.0b013e31821ece12.

23. Schneider PL, Crouter SE, Bassett DR. Pedometer measures of free-living physical activity: comparison of 13 models. Med Sci Sports Exerc. 2004;36(2):331335; doi: 10.1249/01.MSS.0000113486.60548.E9.

24. Snijders TAB, Bosker RJ. Multilevel analysis: an introduction to basic and advanced multilevel modeling. London: Sage; 1999.

25. Staudenmayer J, Zhu W, Catellier DJ. Statistical considerations in the analysis of accelerometry-based activity monitor data. Med Sci Sports Exerc. 2012;44(1 Suppl 1):S61-S67; doi: 10.1249/MSS.0b013e3182399e0f.

26. Bland JM, Altman D. Statistical methods for assessing agreement between two methods of clinical measurement. Lancet. 1986;327(8476):307-310; doi: 10.1016/ S0140-6736(86)90837-8.

27. Huang Y, Xu J, Yu B, Shull PB. Validity of FitBit, Jawbone UP, Nike+ and other wearable devices for level and stair walking. Gait Posture. 2016;48:36-41; doi: 10.1016/j.gaitpost.2016.04.025.

28. Campbell KL, Crocker PR, McKenzie DC. Field evaluation of energy expenditure in women using Tritrac accelerometers. Med Sci Sports Exerc. 2002;34(10): 1667-1674; doi: 10.1249/01.MSS.0000035995.09097.2d.
29. Steeves JA, Tyo BM, Connolly CP, Gregory DA, Stark NA, Bassett DR. Validity and reliability of the Omron HJ-303 tri-axial accelerometer-based pedometer. J Phys Act Health. 2011;8(7):1014-1020; doi: 10.1123/ jpah.8.7.1014.

30. Freedson PS, Melanson E, Sirard J. Calibration of the Computer Science and Applications, Inc. accelerometer. Med Sci Sports Exerc. 1998;30(5):777-781; doi: 10.1097/00005768-199805000-00021.

31. Monteiro CA, Conde WL, Matsudo SM, Matsudo VR, Bonseñor IM, Lotufo PA. A descriptive epidemiology of leisure-time physical activity in Brazil, 1996-1997. Rev Panam Salud Publica. 2003;14(4):246-254. 